Article

\title{
Preservation without Representation: Making CLG Programs Vehicles for Inclusive Leadership, Historic Preservation, and Engagement
}

\author{
Andrea R. Roberts $($ ) \\ College of Architecture, Texas A \& M University, College Station, TX 77840, USA; aroberts318@tamu.edu \\ Received: 15 July 2020; Accepted: 4 August 2020; Published: 11 August 2020 \\ check for \\ updates
}

\begin{abstract}
This article examines public historic preservation agencies' ability to support social inclusion aims within the context of the Certified Local Government (CLG) program. Though administered by the Texas Historical Commission, Texas' State CLG program is federally-funded and makes available special access to technical assistance, grants, and loans to qualifying communities contingent on compliance. Program surveys the state staff administered to city and county historical commissions with the CLG designation indicate challenges around diversifying their leadership and identifying training opportunities. This article reviews those surveys to detect insights into how the state CLG program can create spaces in which local commissions can increase their "representativeness" through changes in assessment and training content. Specifically, I analyze two government assessment tools used to evaluate local CLGs' ability to meet federal and state training and participation expectations. I compare these survey results to self-assessment activities and questionnaires collected during a pilot training on implicit bias, outreach, and cultural resource surveying I conducted with multiple CLGs in Gonzales, Texas. Findings suggest more creatively designed training and capacity building is necessary around inclusion, identifying structural barriers to participation, and foundational knowledge of historic preservation and planning practice, and ethics.
\end{abstract}

Keywords: public administration; historic preservation; public history; cultural resource management; storytelling; urban planning; social inclusion; structural racism; implicit bias; engaged research

\section{Introduction}

The United States' Certified Local Government (CLG) program, administered jointly by State Historic Preservation Offices and the National Park Service CLG Office, links federal dollars to hyperlocal preservation efforts and is mediated by each state's historic preservation agency. County and city-level historical or landmark commissions are the organizations that participate in the federally-funded Certified Local Government (CLG) program, which makes available special access to technical assistance and grants to qualifying communities. Though meant to support local engagement and to make funding available for preservation activities and projects, state agencies that administer the program have struggled to address a lack of diversity among city and county historical commissions. A failure to practice social inclusion and promote knowledge about historic preservation may make the program less sustainable over time because their leadership will not reflect, engage, or sustain the interest of the local population in activities and fundraising. CLGs are currently evaluated based on factors that do not explicitly assess the efficacy of their current outreach to Black Indigenous and People of Color (BIPOC) groups and these designees' ability to diversify local leadership. This article explores these under-investigated dimensions of equity and inclusion in process and outcome, and argues that they can be incorporated into Texas' state CLG program. The question driving the analysis and this article is, how can CLGs, particularly city and county historical commissions, be encouraged to embrace 
actionable, inclusion-centered goal-setting, and programming during State Historic Preservation Office (SHPO)-sponsored training?

Studying state-level CLG programs can be instructive, because they have considerable autonomy over their operations. They can, for example, decide to require certain trainings or conversely allow CLGs without preservation ordinances to still participate in the program. Each of the CLG grants are tagged by categories based on state plan priorities, not national ones. For example, Texas' current state plan goals include increasing opportunities to learn and experience history through place, with a measurable outcome being, "increased participation of underrepresented people in historic preservation" and more creative outreach to diverse groups [1]. An additional priority is increasing the diversity of property designated types, particularly cultural landscapes.

The Texas CLG program has an active program. The data for the period studied contains an assessment of 74 communities participating in the certified local government program. However, in 2020, that number increased to 77 (Figure 1). Almost all CLGs are city or county historical commissions in Texas. However, not all county historical commissions are CLGs. Only 18 of the state's 236 county historical commission are also CLGs. The remaining CLGs (56 in this study) are city-based historical or landmark commissions. While all CLGs have the same training requirements, it is essential to note that county historical commissions engage in several activities unrelated to national register designations. County historical commissions are supposed to promote countywide awareness of historic preservation, promote historic and cultural sites in the county to sustain heritage tourism, operate and manage any museum owned or leased by the county, acquire artifacts and supervise staff at any county museums. Furthermore, county historical commissions are not 501c3s but are instead considered political subdivisions. As such, county historical commissions wield considerable influence over historic preservation activities and consequently zoning and land use broadly [2].

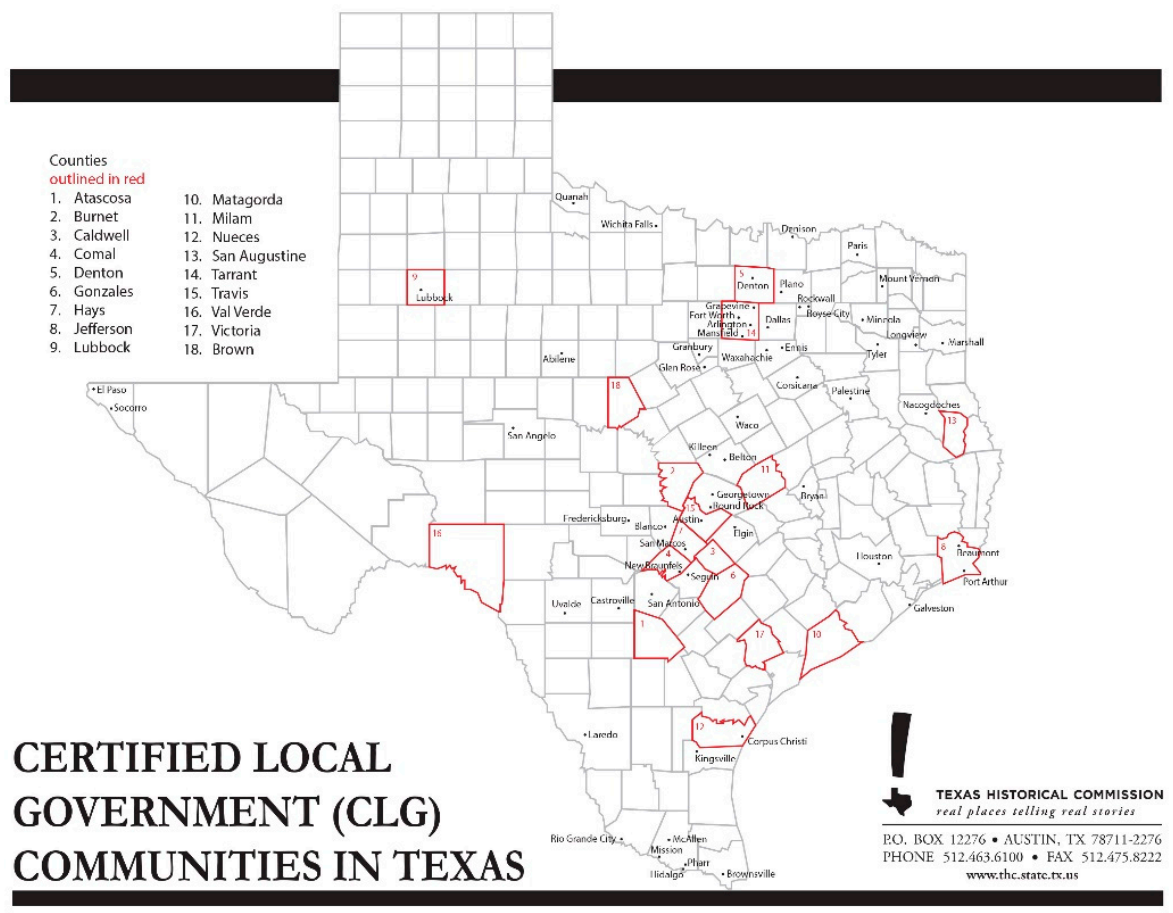

Figure 1. This July 2020 map contains 77 cities and counties considered Certified Local Government Communities. Source: https://www.thc.texas.gov/preserve/projects-and-programs/certified-localgovernment/certified-local-government-communities.

In 2017, grants through the 10\% allocation from the SHPO to the program resulted in USD 160,250 being awarded to 10 grantees. Through an examination of self-assessments associated with local groups that hold the CLG designation in Texas and program evaluation that the state agency staff administers, 
I bring attention to the opportunities preservation agencies have to better serve the public interest through improved assessment and training. Specifically, the article examines how members perceive, and whether they can address, three common shortcomings among city and county CLGs-a lack of diversity among leadership, poor engagement with underrepresented groups, and inadequate training. I examine assessment because it exists at the intersection of access to funding, compliance, and social inclusion.

In addition to assessment, the CLG staff also schedules and designs workshops around the state each year to address local historical commissions' challenges emerging from these reports. Texas' local historical commissions have reported problems around diversifying their leadership and outreach to diverse groups. Often, commission leadership is greyer and whiter than the communities for whom they make decisions about public history and preservation. These external and self-assessments prompted the state CLG program to seek my assistance as someone who has successfully integrated engagement with diverse, underrepresented groups into my research practices. As a result, I conducted a workshop that provided strategies for meeting outreach and engagement challenges at one of these CLG trainings in exchange for the opportunity to develop a future pilot, study of historical commissions and to share a new archiving tool, The Texas Freedom Colonies Atlas, which challenges several assumptions around the significance and integrity which govern designations. This article compares annual self-reporting and State Historic Preservation Office (SHPO) reviews of CLGs in Texas conducted every four years to my in-person administration of self-assessment surveys at a workshop co-hosted by a county CLG and the SHPO's CLG staff.

The training was conducted with CLGs from multiple counties at an event held in Gonzales, Texas, to explore ways new workshops may shift attitudes, and equip local preservationists with the capacity to diversify local leadership and increase collaboration with preservationists of color in their communities. Self-assessments and other materials from exercises performed by CLG training participants indicate a need for more training and capacity building around diversity and inclusion. Specifically, the training introduced new definitions and benchmarks, signifying progress in the areas of inclusion and diversity. These definitions foreground strategies for diversifying not only designations but also commission leadership, activities, and relationship building.

To explore these questions practically, I discuss a CLG pilot training on implicit bias and how to leverage a cultural resource survey and mapping tool to engage underserved communities. Descriptions of the results of each of these trainings, I argue, indicate a need to consider requiring CLGs to participate in regular annual workshops related to inclusion, altering reporting and eligibility, and make inclusion and anti-bias training compliance part of the review conducted every four years for all CLGs. Additionally, the testing of these local-level inclusion training compliance reviews can help the National CLG program test new ways to affirmatively further ${ }^{1}$ inclusive preservation outreach and leadership among member CLGs [3].

Experimental learning activities and self-assessment tools at the pilot workshop prompted me to ask an overarching question: might more trainings dedicated to promoting inclusive leadership and equitable funding allocation aid overall CLG performance, particularly their capacity to not only increase the number of properties associated with diverse heritage added to the national register, but also to make local leadership reflect the ethnic, age, and geographical makeup of a CLG's community? Self-assessments and report evaluation approaches are examined to determine if current measures used to assess the progress and performance of CLG programs include consideration of the inclusion of underrepresented groups. The findings led me to conclude that at the intersection of preservation policy, diversity, and intergovernmental agency performance emerges an equity gap.

1 Though it is a fair housing term, "affirmatively furthering" is meant to refer to concerted, measurable, indefinable efforts to manifest outcome, inclusivity and diversity in preservation outreach, leadership, and access to resources. I argue this term could be adapted as an overarching category for actions and preservation regulations that require consultation and fostering participation with underrepresented groups in a way that can finally be monitored and enforced. 
To address the gap, training, and more sophisticated outreach and engagement strategies, as well as new approaches to assessing the efficacy of the CLG program, are necessary.

The article explicates how Texas' CLG program has included inclusion as part of their training, grant application scoring, and annual reporting. Then the article examines Texas SHPO's CLGs as a case study of a state grappling with how to integrate more diversity and inclusion into its CLG program. Special attention is given to underrepresented groups and local leaders whom I taught new ways to leverage surveying projects to diversify and grow local leadership in preservation. Recurring themes are identified, indicating a need for more intensive, creative trainings. Finally, the training introduced various ways to define and measure progress aside from those presented in the current annual reporting.

I argue that representativeness and inclusion, as core performance measures of both processes and goals, matter. Furthermore, an approach to inclusion rooted in both distributive and procedural justice to assess progress and reform the program is necessary. I argue that a specific type of diversity, "representativeness," is what the state CLG office should demand from the local commissions participating in the program. That is, more diverse leadership reflecting an entire community's cultural and socioeconomic makeup increases the likelihood of commissions undertaking projects in their counties and cities, reflecting underrepresented groups' priorities (not just designation), thereby supporting distributive justice. More simply, to make CLG leadership and programming reflective of the local population, and project funding equitable, increased training and monitoring of local leadership's efforts to confront bias and power dynamics need to be made a priority. CLG leadership must include people from a variety of classes, racial and ethnic groups, and ages. Procedural justice is served through the equitable provision of training to diverse members of the community to build capacity and future leadership that is not exclusively white and older, as is the case among Texas' local historical commissions.

\subsection{National CLG Program Design, History}

While CLG requirements vary by state, each program is required to meet minimum federal requirements. All CLGs must establish a preservation commission, enforce state or local legislation for the designation and protection of historic properties, maintain an active survey of local historic resources, and provide for satisfactory public participation in the local historic preservation program (including the National Register process and other activities). Adequate public participation, relevant assessment, and training are of specific concern in this article.

There are several benefits to being a CLG. For example, becoming a CLG makes that community eligible for competitive grant funding, technical assistance, and access to training. Funding can be used to finance surveying, National Register nominations, rehabilitation work, design guidelines, educational programs, training, structural assessments, and feasibility studies.

The program requires that each state set aside annual appropriations from the Federal Historic Preservation Fund and give at least $10 \%$ of that funding to CLGs as subgrants. A funding source for the CLG program is The Historic Preservation Fund (HPF), which was not officially empowered by Congress to carry out its duties until 1976. Though USD 150 million should be deposited annually into the fund through FY2023, Congress appropriated USD 49.7 million in FY2019 and USD 52.7 million in FY2020 for SHPO grants in-aid. Then 10 percent of each state SHPOs allocation is made available for regranting to a state's certified local governments, though each state has the option to allocate more. Individual SHPOs can set grant requirements and eligibility.

CLGs are eligible for several grants which promote diversity through surveying and listing of diverse American history. In the list of statutorily qualified applicants for federal preservation funds are CLGs. Grants include the African American Civil Rights Grants and Underrepresented Community (URC) Grants, which can aid in promoting inclusion. The oldest of the competitive grant programs the office administers is the Tribal Heritage Grant. Note that Tribal Historic Preservation Offices (TBHOs) areas of interests rarely include government subunits. As a result, the allocations to states go to and are 
administered by the TBHOs. However, at times, when ancestral lands are elsewhere, TBHOs within one state may be contacted by a SHPO from another state. According to David Banks, Preservation Planner at the National Park Service's (NPS') CLG program, a majority of the federal office's efforts are focused on grant applications and agreements, adding project descriptions to a central database, reviewing state plans and ordinances for all the state and individual applicants across the United States rather than enforcement or training types ${ }^{2}$.

However, CLGs must build the capacity to conduct and administer grants, and that requires training qualified staff and compliance with annual reporting. Through this devolution of federal power to the local level, equitable distribution of funds and resources to underserved groups may be inhibited or incentivized based on the types of programming and reporting required of CLGs. Reports include current evaluation of performance based on the number of projects dedicated to inventory (survey), local landmarks, local tax incentives, local grants and loans, local design review, and local property acquisition. States have reporting requirements that enable national tracking of these areas of performance. States have to conduct four-year reviews of CLGs to assess compliance and make recommendations and complete annual reports.

Very little literature focuses on issues of power, inclusion or representativeness as it relates to the CLG program. Where it is present in preservation literature, CLG member organizations are characterized as abstract information distribution points for outreach and volunteer mobilization purposes [4]. Cultural, racial, ethnic, economic, language, citizenship status, ability, or age-based representation of local commissions and boards in municipal contexts is a subject examined in passing in some public administration literature, but less so in historic preservation or heritage conservation specifically, except indirectly as a critique of the NPS' focus on surveying and enforcing standards which marginalize properties associated with underrepresented groups. J.A. Nicolay, a public administration scholar, refers to CLG organization members as "citizen as administrative participants"(p. 391) who provide, "a resolve of the techno-democratic tension, tensions of the market economy, and tensions between government and citizen" [5] and are given a unique opportunity to represent the public interest. CLGs, made up of what constitute local volunteer boards and commissions, enable public boards to "(a) provide legitimate outlets for the energies of democratic citizenship; (b) provide expert policy interpretation and execution; (c) provide a forum for public debate and enlightenment; and (d) provide a filter buffer interface for the career public administration and the elected council board" [6] (p. 401). "Public administration programs should be expanded to train these citizens with a core program embracing issues of governance, administrative legitimacy, and public management" [6] (p. 382). However, Nicolay focused on the function of these boards as they relate to specialized zoning processes-specifically the historic architectural review board.

While there are several dissertations and theses that are case studies of CLG and boards as examples of citizen participation in preservation, none contend with the lack of representativeness on these volunteer boards, which make up local level member CLG organizations. Some authors argue that a group having been designated as a CLG is an indicator of the community's involvement and "high level of commitment to historic preservation" [7] (p. 10).

Some urban planning scholars have suggested that there are untapped opportunities for furthering sustainability and enhancing local planning capacity through Certified Local Government programs. Appler and Rumbach (2016) argue that CLGs enable local governments to develop a historic preservation infrastructure because the program requires establishing or working with the local historical commission [8] (p. 99). They add that CLGs also help communities develop historic preservation ordinances leading to the surveying of potentially significant properties and that these local groups could aid in coordinating flood and other disaster planning to protect historic properties Others have encouraged the program to enhance its funding availability and to enforce compliance

2 Banks, D., NPS, CLG Program Staff, Interview by Andrea Roberts, Telephone, 31 July 2020. 
with requirements [9] (p. 58). An additional way that CLGs can strengthen local preservation and civic life is through trainings forcing self-assessment and confrontation with implicit bias and racism in public history and leadership. Such concerns are only discussed in grey literature such as annual reports, state preservation plans, and one book chapter, but not peer-reviewed journals. Issues of inclusion, equity, and representativeness are absent from scholarship assessing the CLG program and its activities though the rest of society sees an urgent need to reckon with these matters [10].

\subsection{DEI and Historic Preservation}

Conversations around diversifying historic preservation's local commissions are occurring alongside national discourse on inclusion and social justice in various sectors and in civic life. In the wake of the death of George Floyd and an increasing validation of the tenets of the movement for Black Lives, public and private institutions have engaged in new diversity, equity, and inclusion (DEI) initiatives with performative fervor. Consequently, statements and proclamations made on behalf of predominately white or white-led institutions have been pressured to espouse DEI with associated accountability measures in place. Calls for anti-racism and equity in historic preservation and allied fields have consisted of statements on one end of the spectrum to a wholesale questioning of the relevance of the field and DEI terms on the other $[11]^{3}$.

In this article, the use of the word diversity is better characterized as "representativeness," which is "the extent to which an organization reflects constituent characteristics in its governance or operations" [12]. Representativeness encompasses racial, ethnic, religion, educational attainment, age, culture, occupation, and gender composition of personnel as well as biological and socioeconomic positionalities. Inclusion is about creating a sense of belonging rooted in a transformation of the shared basis upon which an institution and its mission are built. Equity, however, requires confronting and addressing through policy and procedural changes, the disparate impacts that systemically create predictable patterns of "the distribution of preservation's benefits and costs" based on social or cultural factors [13].

For example, disproportionate impacts of preservation regulatory policies on African American and vernacular landscapes and structures is one example of systemic racism promulgated through the Secretary of Interior standards and the National Register of Historic Places designation criteria. Ryberg-Webster explains well the field's oxymoronic posture when talking about debates about the just approach to preservation advocacy on behalf of African American sites. She explains that while an under-designation problem is apparent, the high architectural standards informing National Historic Preservation Act (NHPA) standards make it impossible for the same sites to be designated [14]. Randall Mason, Richard Longstreth, and Vincent Michael echo these critiques of the standards pointing out ways the regulations subordinate local and cultural significance to criteria rooted in architecture [15-17].

While the CLG program, through its focus on listing and designation using National Register of Historic Places criteria and the Secretary of the Interior's Standards are aspects of systemic racism in cultural resource management writ large, there are other ways in which anti-blackness and oppression manifest in preservation that must concurrently be addressed. Representativeness and participation in preservation practice and education remains a serious barrier to systemic change in the field. Awareness of the need for more participatory preservation is high. However, locating the literature about the demographics of who participates is rare. Erica Avrami explicates the state of research about participants in preservation: a notable exception comes from recent findings that in New York City, interest in preservation tends to come from whiter, older, and wealthier people, who are primarily concerned with physically oriented aesthetic and associative values [18]. There has also been little

3 Conference topics reflecting the dismantling posture explored challenging implicit bias, the pool of investors funding real estate projects, managing to center BIPOC voices even while engaging in traditional preservation research and practices such as nominations and listings, and a labor equity platform. 
research on the diversity of heritage practitioners themselves, though this is a critical area of concern. Arlotta and Avrami reference Antoinette Lee, a historian with the National Park Service, who was one of the first to argue that the preservation field needs to "look like America." Demographic information on practitioners is scarce; note Arlota and Avarami who cite Keilah Spann who explains that people of color accounted for only 10 percent of degrees awarded in historic preservation graduate programs in 2014 [19].

Justin Moore asserts that access to the field for people from diverse backgrounds (representativeness) is key. He writes that good intentions are not enough, and that "it isn't always likely that a place shaped by a select few will fully work to benefit everyone" [20] (p. 21). He adds that the profession needs to reflect the diversity of the country and observes that the problem is not being addressed "at the scale necessary to make a meaningful impact" [20] (p. 21).

While there is literature about engagement and inclusion, there is less about growing diverse leadership, questioning bias, and sharing power in preservation. In recent years urban planning has engaged this deeply through a special issue on Arnstein's ladder of participation on the 50th anniversary of the landmark work in participatory planning that interrogates questions of citizen control and power during engagement. The volume includes a piece on engagement in historic preservation, called "Remixing as Praxis" about grassroots preservation practice [21]. Another volume on participation and inclusion in preservation has been published recently by Columbia University Press. Other work on participatory preservation addresses questions of diversity and barriers to inclusive engagement during surveying [22]. Other research argues that more engagement should occur at the intersection of participatory preservation and interdisciplinary action research [23-25].

Critical urban planning scholarship has long challenged issues of power in planning processes and prescribed reflective practices requiring recognition of how a planners' positionality impacts the research or planning context. Elizabeth Sweet characterizes the optimum planning posture as one in which one possesses 'cultural humility' [26]. Sweet cites Tervalon and Murray-Garcia's (1998) definition of cultural humility, which is "a practice of and ongoing commitment to self-evaluation and self-critique by professionals for the purpose of rebalancing power inequities. The goal of cultural humility is for practitioners to develop "nonpaternalistic" collaborations with communities [27] (p. 117) and to "relinquish" their position as expert" [26,27] (p. 5). Implicit bias is embedded in more than regulations but also entrenched in preservation leadership, which I believe operates from what Ramon Grosfoguel calls a false universality or "God's eye view," during decision-making, planning, budgeting, and assessing progress $[26,28]$ (p. 6) ${ }^{4}$.

Changing regulations is one matter, but leading professionals and community leaders through a process that prompts them to reconceptualize their political posture is another. Creating spaces and moments in which cultural humility can emerge is a precursor to authentic engagement, inclusion, diversity, and equity because this process addresses power dynamics. I lead CLGs through activities that force them to confront the power and control predominately white leadership wield through the promotion of public history from a God's-eye view in the Texas case study.

\section{Method and Materials: Texas CLG Program Assessments}

The approach taken to evaluate the efficacy of state efforts to promote social inclusion and increase local participation and capacity includes analysis of responses to two assessments, design and analysis for another evaluation I administered at a workshop, and observation of workshop activities. The workshop is at the core of the research design and was created in partnership with the CLG

4 Grosfoguel describes the God's Eye View. Thusly, "It is this 'god-eye view' that always hides its local and particular perspective under an abstract universalism. Western philosophy privileges 'ego politics of knowledge' over the 'geopolitics of knowledge' and the 'body-politics of knowledge'. Historically, this has allowed Western man (the gendered term is intentionally used here) to represent his knowledge as the only one capable of achieving a universal consciousness, and to dismiss non-Western knowledge as particularistic and, thus, unable to achieve universality ". 
staff. However, I leveraged my experiences deploying an engaged research approach—collaborative storytelling, co-design, ethnography, and self-assessment, primarily with underserved communities in rural areas-and adapted them to these mostly Anglo workshop attendees from cities and towns in central Texas [21]. In this instance, the collaborative storytelling and self-assessment approach was redesigned to support the staff's desire to expose attendees to creative surveying while exploring bias, social exclusion, and gaps in planning and preservation knowledge among CLG-designated commission members in attendance. The previous instances in which I applied engaged design were informed by various methods, including qualitative and ethnographic methods such as collaborative storytelling, observation, and questionnaires designed to aid self-assessment [21].

I first examined the content and results of Texas CLG policies, procedures, and survey questions. In recent years, the Texas CLG program has endeavored to address outreach, training, and inclusion as inextricably linked areas of performance. Texas CLGs must attend at least one training a year, and noncompliance can lead to decertification. Most notably, they require that CLGs explain how their programming, training, and grant applications support the goals and objectives of the state preservation plan, which prioritizes increased outreach and diversity. Further, the CLG program has included consideration of diversity in grant scoring. The applicant can be awarded up to three points in the category "Public Involvement and Deliverables," which is a total of 13 of the 100 possible points. Those three points are available if the CLG applicant affirmatively answers the question: Does the project address or benefit an underrepresented group within the community?

They have also required that CLGs address in their annual and four year reviews questions assessing leadership representation and diversity. Annual reports ask applicants, "Do the members of the CLG Committee represent the general ethnic diversity of the community?" Responses to the question in annual reviews (Table 1) from the last three years show $17 \%$ of local CLGs self-assessed themselves as not reflecting the makeup of the community, $24 \%$ in 2018 , and $26 \%$ self-assessed the same condition in 2019 [29]. On average, the percentage of those who don't think their leadership reflected community make up in 2019 was $26 \%$, an increase of $24 \%$ over 2017 according to annual surveys distributed to 74 CLGs. The table indicates the number of surveys returned and responsive to the question of the 74 CLGs each year.

Table 1. Responses to Question 15: Do the members of the Preservation Commission represent the general ethnic diversity of the community?

\begin{tabular}{cccc}
\hline & $\mathbf{2 0 1 7}$ & $\mathbf{2 0 1 8}$ & $\mathbf{2 0 1 9}$ \\
\hline CLGs Responsive & $89 \%, 66$ & $91 \%, 69$ & $85 \%, 63$ \\
Response: No & $17 \%, 13$ & $24 \%, 18$ & $26 \%, 19^{1}$ \\
\hline
\end{tabular}

${ }^{1}$ Texas Certified Local Government Annual Reports, Fiscal Years 2017-2019, Texas Historical Commission Certified Local Government (CLG) Program Office, $\mathrm{n}=74$.

In 2017 (chosen because it was the year with most reviews-26), the four-year evaluations the that Texas Historical Commission (THC)'s CLG staff conducted reported that only 23 percent (6) had compliance issues, while four answered "no" to the leadership representation question. Compliance issues were, in almost every case, about the lack of skilled staff. A particular shortcoming for those out of compliance was having a historic preservation officer (HPO) without a preservation-related degree. Two of the CLGs reviewed had compliance issues related to lack of board commission training or lack of Historic preservation officer (HPO) training. While many participated in outside trainings, there was no clarity around whether the workshops CLGs reported attending addressed diversity, inclusion, leadership, and outreach to underrepresented groups. It is important to note, however, that rates of participation among traditionally marginalized populations are fundamentally a structural issue. Many local CLGS consistently out of compliance, have small populations and tax bases, are understaffed, and have few individuals aware of how implicit bias may be impacting their 
preservation work. Further, most of these communities lack preservation staff of color. These structural issues exacerbate already low training compliance and a lack of diversity among CLG leadership.

\section{Alternative Assessment: CLG Outreach and Diversity Training, Gonzales County, Texas}

I was invited to Gonzales to lead a workshop organized by the Gonzales County Historical Commission in partnership with the Texas Historical Commission's CLG program. As part of the 1 August 2018 workshop, I led a training introducing attendees to the concept of implicit bias as well as ways to include more African Americans in cultural resource survey processes. The workshop began with introductions from elected officials. I then led a storytelling activity called "Is My Story Your Story," designed to confront biases in how individuals interpret their relationship to community history based on their identity [10]. After this activity, I transitioned into a presentation on the meaning of implicit bias, and current challenges CLGs report having as they relate to outreach and diversity. Then participants were asked to gather in groups (associated with shared county or city affiliation) to complete a self-assessment. After selecting a representative from each of their group, they were then asked to share their assessment results. I followed that activity with my own research experiences identifying and mapping historic African American settlements known as freedom colonies. The intention was to make my engaged research strategies available to the attendees so that they could adapt them for their outreach to BIPOC communities. They were then led through a process of setting new goals for inclusive leadership and creating the beginnings of a new outreach plan. Staff from the state CLG program helped facilitate the workshop and provided some information about the CLG's policy and grant programs.

The goal of the new training was to expose CLG members to new ways to affirmatively further inclusive outreach, cultural resource surveying, and diversifying leadership all at once [3]. I co-planned a summer event with the CLG program staff at THC [10]. We discussed the prospect of training that focused first on encouraging increased African American surveys, specifically Emancipation and Reconstruction Era communities called freedom colonies. While planning the training, we discussed ways that a workshop on surveying may open the door to talk about ways to collaborate with stakeholders from the diverse communities being surveyed. Gonzales County's Historical Commission had expressed an interest in a collaborative surveying project and agreed to host the training.

Gonzales was particularly appropriate for this meeting because of its place in early Texas history. Considered the "Lexington and Concord" of Texas independence, Gonzales' Anglo settlers refused to return a cannon given to them by the Mexican government- thus the saying "Come and Take It," used to market the town [30,31]. Daring the Mexican government to retrieve its cannon was a proxy for Texans' conflict over their right to own slaves. Despite the passage of time, the overarching white settler narrative still dominates local public history and preservation.

Training attendees from the host county and at least six other CLGs from central and southern Texas attended. There was a total of 36 attendees. An agenda I distributed at the training provided five goals:

- Unpacking our perspectives on public history using our core stories

- Identify implicit bias in preservation leadership and public history in Texas (Anglo emphasis)

- Learn from an example of marginalized history and grassroots preservationists; freedom colonies and freedom colony descendants

- Identify new outreach strategies from the workshop leader's freedom colony research experiences

- Making a project-based outreach plan for your CLG

The workshop was held at Providence Missionary Baptist Church, a historic African American site in Gonzales. The training included a storytelling ice breaker, in which all attendees were invited to share their core stories and relate them to the foundational stories of communities in Texas. Centering people of colors' stories was a foundational shift for the county commissioner, county historical commissioners, and other leaders present. Predominantly white women, these lay preservationists mediate federally mandated consultation with interested parties to federally funded project applications, event planning, 
and survey funding. Many of these leaders proudly presented their origins back to the Republic of Texas, including the "Old Three Hundred," the first recipients of land grants in Texas [10].

A storytelling activity provided a bridge to a contemporary conversation about how such stories reinforce fissures and reify white leadership in local preservation organizations. Attendees were then led through an exercise in which they were introduced to and asked to apply practical steps toward diversifying leadership and outreach activities (Figure 2).

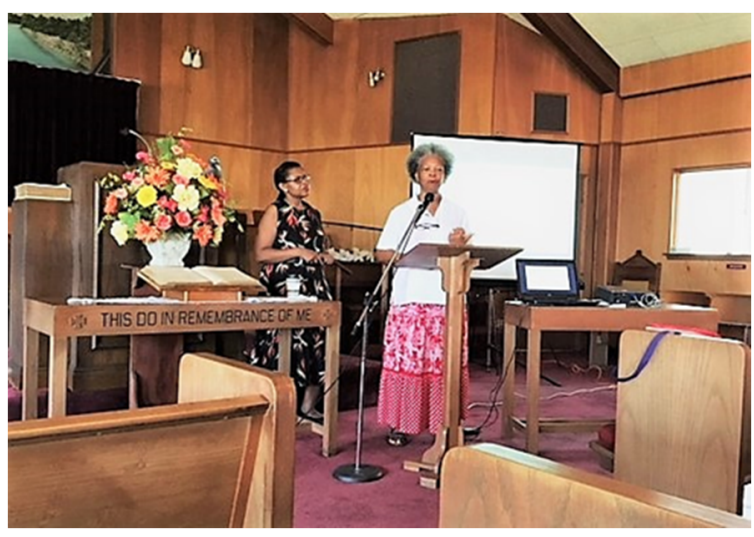

(a)

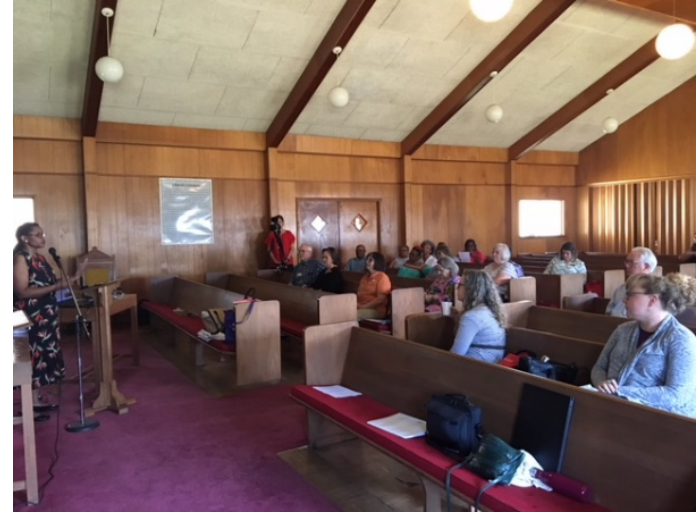

(b)

Figure 2. The CLG Workshop, held August 1, 2018, was co-hosted by the stat CLG program, the County Historical Commission, and the local Edwards Association-an African American group dedicated to the preservation of a historic African American School in Gonzales. The images show participation in a storytelling exercise (a) and the author leading the workshop through a self-assessment exercise to be performed in small groups $(\mathbf{b})$.

In addition to self-assessment, participants were introduced to freedom colony preservation, and The Texas Freedom Colonies Project Atlas, an online mapping tool [10]. Workshop participants were invited to use the tool or paper surveys to collect and store data about newly identified African American settlements. The next stage of the workshop took on a lecture format and included an overview of implicit bias and how it manifests itself in local preservation planning and surveying. I then asked attendees to suggest ways they could engage in inclusive storytelling on a local level.

They began with a self-assessment survey which included the following questions:

1. What are the strategies your organization uses to invite the public to participate in events, fundraisers, or preservation projects?

2. Which strategies does your organization use to recruit leadership?

3. Do you use different strategies for outreach to underrepresented groups? What are these strategies?

4. Using a letter grade, how would you assess your efforts to recruit diverse leadership or create inviting spaces for diverse groups at your events and meetings?

5. What are the challenges (or breakthroughs) you have faced when attempting outreach?

6. How do you collaborate with underrepresented groups?

7. What are the current barriers to engagement? (scenarios, anecdotes )

8. How have these challenges shaped your approaches to outreach or setting priorities?

9. What has worked?

10. Why do you think your altered strategies worked?

The first question, what are the strategies your organization uses to recruit leadership, and the third, asking them to give themselves a performance-based letter grade are the two used to identify themes and trends which are relevant to this article's inclusion, outreach, and leadership focus.

They were then asked to develop an outreach and leadership recruitment plan. Using my outreach to freedom colonies as a model, I shared examples of the types of institutions and events which 
could aid in partnership and help identify new leadership for CLGs (city and county commissions). They were also offered various ways of evaluating or measuring progress in their outreach and leadership inclusion efforts. I asked them to examine their commission budget allocations and to broaden what they define as diverse. Among the dimensions of diversity, they were asked to consider in programming, leadership, and outreach were ethnicity, race, gender, income, language, and areas of their county or city not previously engaged. I also introduced attendees to Arnstein's ladder of participation and its application in planning and grassroots preservation [32]. "The ladder" is a scale of authentic, meaningful engagement ranging from manipulation to citizen control. The aspiration is citizen control, and these helped participants refine their ideas about what progress would look like for their community. They were also asked to think about scholarship programs that could increase youth interest in preservation activities.

To bring together African American and white preservationists, Gordon co-planned her event with the Edwards Association. The Edwards Association then hosted a lunch and led attendees on a tour of a historic African American school Figure 3. Even while the workshop attendees toured the school and met African American preservationists, they continued to relay to me the problems they had developing partnerships with BIPOC groups in their own communities, instead of connecting directly with hosts on these topics.

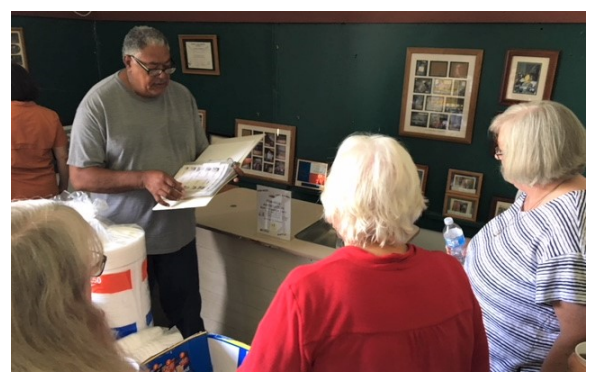

(a)

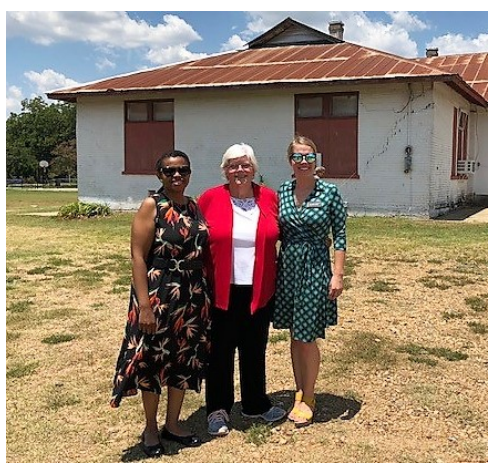

(b)

Figure 3. The CLG Workshop, held 1 August 2018, was co-hosted by the state CLG program, the County Historical Commission, and the Edwards Association-a local African American group dedicated to the preservation of a historic African American School in Gonzales. (a) Edwards Association director, David Tucy, leads a tour through the historic school during lunch. (b)Pictured l. to $r$. Workshop presenter, Glenda Gordon, and Madeline Clites, Texas Historical Commission (THC)-CLG program manager. All images by Texas Historical Commission.

\section{Results: Comparing Government Assessment to Assessment Influenced by Engaged Research Methods}

The trends in assessments administered by CLG staff based at THC's Austin headquarters when compared to those I collected during the workshop (containing a subset of CLG members) reveal similar themes. However, the assessments utilized during the workshop expose more significant insights into why diversifying leadership was such a challenge when compared to the results of annual and quadrennial assessments which the CLG staff administers.

Glenda Gordon, chair of the Gonzales County Historical Commission and event co-host, modeled ways that others in the audience could illuminate their discomfort and biases. Gordon, for example, cautiously shared that she thought that local bias toward a particular narrative about Gonzales centering Anglo settlers was problematic.

Recurring themes among responses to the question about strategies revealed a sense of helplessness among white attendees. Many turned the question back on me, the workshop leader, as if to say, "that is a good question", "I have no idea!" Others shared that they used networking and social media, techniques which are likely to reinforce connections to people like themselves within existing social 
circles. Similarly, others said they look among existing leadership in the business community or seek volunteers through word of mouth. African Americans in attendance used flyers at churches, schools, and newspapers. Professionals in the audience affiliated with cultural institutions or cultural resource management mentioned some targeted approaches such as analyzing current board and committee composition and paying particular attention to talents and demographics to determine which gaps need to be filled among county or city commission leadership. Others complained that after asking for volunteers, they would have to beg often or force an existing commission member to lead.

These occurrences are substantiated by other research on barriers to participation. Stephanie Ryberg-Webster's research shows that there are several barriers associated with getting people of color to volunteer in county historical commissions and heritage societies [14]. Barriers include having the time to allocate toward meetings and volunteer activities during regular working hours that retired older, predominately white county historical commission members have. Ryberg-Webster (2017) addresses power dynamics and exclusion arising when engaging these communities during cultural resource surveys. Among factors inhibiting meaningful engagement with African Americans in preservation projects are "perceptions that the practice is elitist, that high-style architecture is valued more than everyday landscapes, and that material integrity trumps social or cultural significance" [14] (p. 7-8). She adds that stringent regulations and varying interpretations of places make organizing sustained projects challenging [14]. Further, mobility and neighborhood change over time alter the percentage of African-American full-time residents in historic neighborhoods, leading to "overall impermanence of African American residents, business operations, and other activities," inhibiting inclusion in cultural resource surveys. Furthermore, too often, lay historians of color do the heavy lifting on educating white preservationists yet receive no financial or in-kind support for their time and expertise [14] (p. 7-8).

During the event, some mentioned engaging in one on one discussions and extending invitations to meetings as well as cultivating new members through mentoring. In other cases, individuals referred or recommended members again reinforcing the existing social circle. Others said it was essential to encourage new members who come with new ideas. Often the process of nomination was completely formal and required a nomination by elected officials such as city council members. These social interactions, however, have the disadvantage of redistributing local preservation power among the same groups over and over again. Most didn't feel they could successfully identify opportunities to redistribute power through recruitment, programming, collaboration, or outreach. Common excuses included, "I tried, but they wouldn't come" "They don't seem to care about their heritage." "Why can't we get those people involved in what we are doing?" Few talked about ways to collaborate or support existing preservation projects that were BIPOC-led. Most workshop attendees from outside Gonzales struggled with finding ways to collaborate or share power with these organizations. The host city said asking groups how they can support or work with them on their high priority projects opens the door to commission leadership. Gonzales's commission used this collaboration strategy. They invited local African American leadership to participate in the pilot training I led and to collaborate on community archiving projects.

The letter grades participants gave themselves were consistent with the results from annual and four-year reviews. When asked to give themselves a grade, $29 \%$ assessed themselves as performing at $C$ or worse, with $25 \%$ of respondents essentially nonresponsive. Some $46 \%$ assessed themselves as being a B or better in a category indicating they believed their performance to be satisfactory. They shared their survey results to have their experience validated and to exchange promising practices. Notably, diverse groups with whom the host had recently started a partnership with on possible surveying projects were present as well.

A common theme across all of the recommendations were opening up their social circles, supporting existing preservation efforts, and always, reflexively evaluating their own bias and blind spots. The THC's CLG program staff requested future training be conducted the following year in June in other communities. 


\section{Conclusions}

There are three areas of improvement for CLGs of concern to the author: representativeness, inclusivity, and equity. These areas of concern converge at, training, assessment, and leadership. I conclude with recommendations related to each of these convergences.

Training. CLGs in Texas suffer from a lack of consistent training and demonstrate some self-awareness of difficulties they have diversifying their leadership. While the state program encourages attendance at their trainings and those hosted at conferences and by professional associations, CLG programs need access to a wider array of training opportunities that explicitly focus on issues of equity and inclusion. Of the 55 trainings offered through the CLG program from 2017-2019, the five most frequent topics of Texas State CLG program trainings were related to the role of the HPO or Commission, review of standards, an introduction to the CLG and surveying, designation processes, and best practices. Of the 55 trainings provided over those three years, only two trainings were exclusively dedicated to outreach and inclusion. There are several other components of and duties of local commissions and boards that inform land use and public history more generally. A preservation certificate program would make a tremendous difference, not because it would include an overview of the National Register of Historic Places criteria, but because it would validate preservation labor and process as modes of civic engagement and participant administration. This certificate would encourage volunteers, through its accessible curriculum rooted in cultural humility, to confront anti-blackness and implicit bias in the current system. Rather than a rehash of ongoing training or architecturally-focused preservation academic programs, the proposed certificate is not to reinforce guidelines but to equip more communities to challenge them and who is permitted to call themselves preservationists.

Using Texas as a pilot, the national program can then consider ways to develop and enforce new regulations that require outreach and diversity plans (focused on a broad construction of representativeness) and monitor implementation of local DEI and anti-racism plans. State colleges and universities should develop non-professional certification programs for cities that offer a mix of planning, engagement, and policy. Further, a training and outreach plan should be developed by master's preservation students in a summer internship with organizations that happen to be CLGs or eligible to be CLGs - county historical commissions. College classes could also support the state CLG in developing sophisticated ongoing reporting and monitoring focused on representativeness, capacity, and equity. A model for this type of partnership exists as part of Texas A \& M's Texas Target Communities, applied service-learning program [33].

There are organizations outside the CLG and public agencies that should be paid to provide workshops or peer-group training. Oddly, the National Alliance of Preservation Commissions (NAPC), which may highlight these issues at annual conferences, offers no training which focuses explicitly on diversity or outreach. Instead, they have a midcentury training in which one of the objectives is to learn about how to engage underrepresented groups during surveying or other training on building public support for initiatives. While NAPC explains that they can develop specialized programs based on local needs, there is still no specific focus on outreach, inclusion, or diversity [34]. Nationally, more significant successes with addressing representativeness in historic preservation organizations have been found in the non-profit sector outside of CLG designated local historical commissions [34-36]. For example, Michelle Magalong writes about the efforts in recent years by various agencies, non-profit and quasigovernmental, to address representativeness. She writes that "the National Park Service has embarked on heritage initiatives to encourage better representation of Asian Americans, Native Hawaiians, and Pacific Islanders, along with African Americans, Latino Americans, Native Americans, women, and members of LGBTQ communities." She explains that these efforts were designed to address barriers to underrepresented communities' participation and to encourage more National Historic Landmark and National Register nominations [37]. After forming the Asian and Pacific Islander Americans in Historic Preservation, a non-profit advocacy group, she found the group's sustainability and success to be attributed to the focus on community-driven engagement and creating an inclusive definition of preservation among a diverse membership and serving as an intermediary translating 
preservationists' regulatory language to community members. This empowered positionality offers one model in which CLGs could rely more heavily on these groups' leadership and appropriately compensate them.

Assessment and Enforcement. I argue that evaluating performance based on inclusivity, representativeness, and increasing access to CLG workshops like the one in Gonzales can enable county historical commissions to diversify their leadership and project types. Along with the nuts and bolts training about CLG program requirements and surveying, space must be carved out for CLG member organizations to analyze the tacit collusion with dominant narratives that overshadows more diverse public histories and BIPOC-led preservation projects in process. The implications of these exercises occurring in state-led processes are substantial. For example, states can make funding eligibility for surveying and listing new sites on the National Register of Historic Places contingent on participation in similar trainings or activities. In Texas, as well as in many other states, county historical commissions are particularly suitable spaces for fostering these values, because they are also the interested parties that are consulted during Section 106 review processes. Further innovations in surveying approaches and platforms that recognize the systemic racism and marginalization of diverse ontologies of place in preservation standards would ideally inform the preservation certificate programs' curriculum [38].

County historical commissions become complicit in the erasure of endangered places if the state CLG program doesn't prioritize member participation in representativeness, equity, and inclusion training. Leveraging these training spaces will enable practitioners and program administrators to examine the ways that biases perpetuate specific statist narratives, which threaten our civic life. What is missing from the evaluation are in-depth training and explicit self-assessment of diversity on national reports with consequences for noncompliance or incentives for compliance. Clawbacks, extra points on grant applications that describe their inclusion initiatives in detail, specialized technical assistance, and cutting off access to allied programs (like the Mainstreet Program) may enforce compliance with inclusion and training requirements.

Leadership. Preservation has consistently been overwhelmingly white in its leadership and reliant on those with architectural expertise. Confronting that reality is key to addressing the field's white supremacist and classist roots demonstrated by early preservation organizations' commitment to enshrining The Lost Cause in public spaces. While systemic racism or what I call "preservation apartheid" [10] is a significant barrier to African American historic sites being included within the National Register, the barriers to representativeness among leadership in the field's professional spaces, institutions, and volunteer culture can be similarly categorized [15]. Furthermore, while scholars have conducted research that unpacks the ways in which preservation policy in the U.S. perpetuates white supremacy and bias, there is much less peer-reviewed research that confronts leadership representation in the field. While the policies emphasize a white socio-spatial interpretation of cultural landscapes, even more oppressive is the suppression or near refusal to acknowledge BIPOC professional and scholarly voices in preservation practice except as individuals offering "input". More simply, the issue of representation is not only about changing the standards of the National Register to reflect the Burra Charter, if the same colonialist and paternalistic leadership dynamics within landmark and historical commissions, boards, and architectural review committees are allowed to flourish and remain overwhelmingly white. For example, CLGs could consult Black-led groups such as The National Association for the Preservation of African-American History \& Culture when soliciting lists of endangered historic sites. Changing disembodied regulations without confronting and engaging in participatory co-planning and decision-making and embracing cultural humility [26] will never "dismantle" or support the reclaiming of institutions-which actually belong to everyone-that is currently dominated by a white, God's eye view [39].

BIPOC must be at the table, even when the table is not set for BIPOC people. Only by creating spaces in which they, non-BIPOC folks, are forced to confront their biases and embrace "cultural humility" are they able to develop more inclusive civic spaces. Historic preservation happens in this civic space. CLGs are those civic institutions and spaces. As Erica Avrami writes in the edited volume, 
Preservation and Social Inclusion, "Preservation institutions and practice that is said to be inclusive in its administration, programming, budget allocation, capacity building, and leadership must be rooted in the idea that heritage and preservation have a significant role" to play in reconciliation and restorative justice. It likewise involves tackling difficult questions about preservation's past and future with reflection and intentionality" [40] (p. 11).

Preservation as a societal force has the potential to shape power dynamics between municipal governments and people, experts, and BIPOC communities. Cities and counties can either promote agency or suppress it [41]. One example is the role San Antonio's Cultural Historian Claudia Guerra plays in expanding access and leveling the playing field to spur increased participation in local preservation. Avrami writes that "as cultural historian with the Office of Historic Preservation in San Antonio, Texas," Guerra "characterizes her role as that of a translator between communities and policy-makers, interpreting values and interests as well as building trust in both directions to achieve mutually beneficial goals. Both Ryberg-Webster and Guerra observe that professional preservationists are not always well equipped to navigate these complex processes of engaging and sharing decision-making with diverse publics" [40] (p. 14). CLG trainings and events provide spaces to hone these skills.

The systemic racism embedded in historic designation regulations is as oppressive and a threat to civic life as the lack of representativeness and capacity among preservation professionals, scholars, and leadership to address equity, representativeness, and inclusion. Where there are publicly-funded preservation institutions and activities, there is an inherently civic space to which all residents of a community should be able to claim a right to engage and even lead.

Funding: This research received no external funding.

Conflicts of Interest: The author declares no conflict of interest.

\section{References}

1. Texas Historical Commission. Texas Statewide Preservation Plan 2011-2020_Updated 2016; Texas Historical Commission: Austin, TX, USA, 2016; p. 38. Available online: https://www.thc.texas.gov/public/upload/ publications/Texas\%20Statewide\%20Preservation\%20Plan\%202011-2020_Updated\%202016.pdf (accessed on 1 August 2020).

2. Texas Historical Commission. Local Government Code, Title 10., Subtitle B. Chapter 318., Subchapter A. County Historical Commission. Government. Available online: https://www.thc.texas.gov/preserve/projectsand-programs/county-historical-commission-outreach/role-chc-appointee (accessed on 29 July 2020).

3. Harvard Joint Center for Housing Studies. A Shared Future: The Duty to Affirmatively Further Fair Housing: A Legal as Well as Policy Imperative. Available online: https://www.jchs.harvard.edu/research-areas/workingpapers/shared-future-duty-affirmatively-further-fair-housing-legal-well (accessed on 1 August 2020).

4. Bernstein, K.; Hansen, J. SurveyLA: Linking Historic Resources Surveys to Local Planning. J. Am. Plan. Assoc. 2016, 82, 88. [CrossRef]

5. Dougherty, G.W., Jr.; Easton, J. Appointed Public Volunteer Boards: Exploring the Basics of Citizen Participation through Boards and Commissions. Am. Rev. Public Adm. 2011, 41, 519-541. [CrossRef]

6. Nicolay, J.A. The Public Board as Public Administration (and Citizens as Administrative Participants). Int. J. Public Adm. 1993, 16, 382-401. [CrossRef]

7. Phillips, R.G.; Stein, J.M. An Indicator Framework for Linking Historic Preservation and Community Economic Development. Soc. Indic. Res. 2013, 113, 10. [CrossRef]

8. Appler, D.; Rumbach, A. Building Community Resilience through Historic Preservation. J. Am. Plan. Assoc. 2016, 82, 99. [CrossRef]

9. Montgomery, S.W. Taking the National Historic Preservation Program to the Next Level. Forum J. 2016, $31,58$.

10. Roberts, A. The End of Bootstraps and Good Masters: Fostering Social Inclusion by Creating Counternarratives; Columbia University Press: New York, NY, USA, 2020.

11. Sarah Marsom. Dismantle Preservation Virtual Unconference. Available online: https://www.sarahmarsom. com/dismantlepreservation (accessed on 28 July 2020). 
12. Miller, J.L. Managing Board Diversity: The Importance of Differentiating between Diversity and Representativeness. In Perspectives on Nonprofit Board Diversity; Miller, J.L., Fletcher, K., Abzug, R., Eds.; National Center for Nonprofit Boards: Washington, DC, USA, 1999; pp. 4-13.

13. Minner, J. Revealing Synergies, Tensions, and Silences between Preservation and Planning. J. Am. Plan. Assoc. 2016, 82, 73. [CrossRef]

14. Ryberg-Webster, S. Beyond Rust and Rockefeller: Preserving Cleveland's African American Heritage. Preserv. Educ. Res. 2017, 9, 7.

15. Mason, R. Fixing Historic Preservation: A Constructive Critique of 'Significance' [Research and Debate]. Places 2004, 16, 71 .

16. Longstreth, R.W. Cultural Landscapes: Balancing Nature and Heritage in Preservation Practice; University of Minnesota Press: Minneapolis, MN, USA, 2008.

17. Michael, V. Diversity in Preservation: Rethinking Standards and Practices. Forum J. 2014, 28, 5-12.

18. Avrami, E.; Leo, C.-N.; Sanchez, A.S. Confronting Exclusion: Redefining the Intended Outcomes of Historic Preservation. Chang. Over Time 2018, 8, 102-120. [CrossRef]

19. Arlotta, A.; Avrami, E. Preservation's Engagement in Questions of Inclusion: A Literature Review. In Preservation and Social Inclusion; Avrami, E., Ed.; Columbia Books on Architecture and the City; Columbia University Press: New York, NY, USA, 2020; p. 228.

20. Moore, J.G. Making a Difference: Reshaping the Past, Present, and Future toward Greater Equity. Forum J. 2017, 31, 19-26.

21. Roberts, A.; Kelly, G. Remixing as Praxis: Arnstein's Ladder Through the Grassroots Preservationist's Lens. J. Am. Plan. Assoc. 2019. [CrossRef]

22. Minner, J.; Holleran, M.; Roberts, A.; Conrad, J. Capturing Volunteered Historical Information: Lessons from Development of a Local Government Crowdsourcing Tool. Int. J. E Plan. Res. 2015, 4, 19-41. [CrossRef]

23. Wells, J.C. In stakeholders we trust: Changing the ontological and epistemological orientation of built heritage assessment through participatory action research. In How to Assess Built Heritage? Assumptions, Methodologies, Examples of Heritage Assessment Systems; International Scientific Committee for Theory and Philosophy of Conservation and Restoration ICOMOS: Lublin, Poland, 2015; pp. 249-265.

24. Becker, D.D.; Fortmann, L. 2008. Participatory Research in Conservation and Rural Livelihoods. Doing Science Together; Wiley-Blackwell: Hoboken, NJ, USA, 2009.

25. Cumming, G.; Norwood, C. The Community Voice Method: Using Participatory Research and Filmmaking to Foster Dialog about Changing Landscapes. Landsc. Urban Plan. 2012, 105, 434-444. [CrossRef]

26. Sweet, E.L. Cultural Humility: An Open Door for Planners to Locate Themselves and Decolonize Planning Theory, Education, and Practice. E J. Public Aff. 2018, 4, 1-17.

27. Tervalon, M.; Murray-Garcia, J. Cultural Humility versus Cultural Competence: A Critical Distinction in Defining Physician Training Outcomes in Multicultural Education. J. Health Care Poor Underserved 1998, 9 , 117. [CrossRef] [PubMed]

28. Grosfoguel, R. Decolonizing Post-Colonial Studies and Paradigms of Political-Economy: Transmodernity, Decolonial Thinking, and Global Coloniality. Available online: https://dialogoglobal.com/texts/grosfoguel/ Grosfoguel-Decolonizing-Pol-Econ-and-Postcolonial.pdf (accessed on 1 August 2020).

29. Texas Historical Commission. CLG Program Staff. In Certified Local Government Annual Report for Fiscal Year 2017-2019; Texas Historical Commission: Austin, TX, USA, 2019.

30. Buenger, W.L. 'The Story of Texas'? The Texas State History Museum and Forgetting and Remembering the Past. Southwest. Hist. Q. 2002, 105, 480-493.

31. Cantrell, G. The Bones of Stephen F. Austin: History and Memory in Progressive-Era Texas. Southwest. Hist. Q. 2004, 108, 145-178.

32. Arnstein, S.R. A Ladder of Citizen Participation. J. Am. Inst. Plan. 1969, 35, 216-224. [CrossRef]

33. TAMU College of Architecture. Texas Target Communities Homepage-College of Architecture. Education, University, College of Architecture, TAMU. Available online: https://tc.arch.tamu.edu/index.html (accessed on 1 August 2020).

34. NAPC. Commission Assistance and Mentoring Program (CAMP) Menu of Trainings (NAPC). Available online: https://napcommissions.org/wp-content/uploads/CAMP-Menu-1.pdf (accessed on 26 July 2020).

35. Kaufman, N. Historic Places and the Diversity Deficit in Heritage Conservation. CRM J. Herit. Steward. 2004, 1, 68-85. 
36. National Park Service. Heritage and History Initiatives within the National Historic Landmarks Program. National Historic Landmarks. Available online: https://www.nps.gov/subjects/nationalhistoriclandmarks/ heritage-and-history-initiatives.htm (accessed on 1 August 2020).

37. Magalong, M. Equity and Social Inclusion from the Ground Up: Historic Preservation in Asian American and Pacific Islander Communities. In Preservation and Social Inclusion; Columbia Books on Architecture and the City; Columbia University Press: New York, NY, USA, 2020; p. 148.

38. Minner, J.; Roberts, A.; Holleran, M.; Conrad, J. A Smart City Remembers Its Past: Citizens as Sensors in Survey and Mapping of Historic Places. In Crowdsourcing: Concepts, Methodologies, Tools, and Applications; IGI Global: Hershey, PA, USA, 2019; pp. 489-516.

39. Lorde, A. Sister Outsider: Essays and Speeches; Crossing Press: Berkeley, CA, USA, 2012; p. 112.

40. Avrami, E. Preservation's Reckoning. In Preservation and Social Inclusion; Columbia Books on Architecture and the City; Columbia University Press: New York, NY, USA, 2020; pp. 11-14.

41. Johnston, R.; Marwood, K. Action Heritage: Research, Communities, Social Justice. Int. J. Herit. Stud. 2017, 23, 816-831. [CrossRef]

(C) 2020 by the author. Licensee MDPI, Basel, Switzerland. This article is an open access article distributed under the terms and conditions of the Creative Commons Attribution (CC BY) license (http://creativecommons.org/licenses/by/4.0/). 